\title{
Etiology, Patterns And Treatment Modalities For Mandibular Fractures
}

Muhammad Asif Shahzad, Momin Ayub Marath, Daud Mirza

ABSTRACT

Objective: The objective of current study was to evaluate the etiology, patterns of presentation, frequency and different treatment modalities for mandibular fractures in patients treated at Lahore Medical and Dental College/Ghurki Trust Teaching Hospital (LMDC/GTTH).

Methodology: This descriptive - cross sectional study was conducted at Lahore Medical and Dental College, Lahore/Ghurki Trust Teaching Hospital (LMDC/GTTH) from March 2015 to September 2017. The current study included one hundred and twelve (112) patients who were indentified having mandibular fractures. Data were collected regarding patient's age, gender, etiology, site of fracture, patterns and treatment modalities and analyzed using SPSS version 20.

Results: The patients' ages were between 3 to 55 years $(24.87 \pm 10.867$, mean/SD). The majority of fractures occurred amongst 21-30 years of age group having female to male ratio of 1:5.6. Road traffic accident (RTA) was the most frequent etiological factor for mandibular fractures in $89(79.47 \%)$ of patients, followed by assaults $11(09.82 \%)$ and fall $07(06.25 \%)$. A total of 189 fractures were recorded in 112 patients giving a mean of 1.7 fractures per patient. Out of 189 fractures, the parasymphysis was the most prominent site of mandibular fractures $(43.39 \%)$, followed by condyle $(22.75 \%)$ and angle (15.87\%). The treatment modality of open reduction and internal fixation (ORIF/ORIF with IMF) was performed in $88(78.57 \%$ ) of patients while closed reduction and indirect fixation (IMF with eyelet wiring/arch bar elastics \& splint fixation) was done in 24 (21.43\%) of patients.

Conclusion: As evidenced by the present study, road traffic accidents are the most common cause of mandibular fractures in young adults, mostly due to violation of traffic rules. These findings highlight the need to reinforce legislation for prevention of such injuries both in children and adults.

KEY WORDS: Mandibular fractures, Road traffic accidents, Open reduction and internal fixation, Etiology

INTRODUCTION:

The maxillofacial area is anatomically the most exposed part of the body, being more susceptible to injuries ${ }^{1}$. These injuries frequently result in varying degree of disfigurement, functional deficit and psychological problems ${ }^{2}$. The sheer pace of modern life with its high speed travels as well as an increasingly violent and intolerant society has made facial trauma a form of social disease to which no one is immune ${ }^{3}$. Mandibular fractures are amongst the common facial injuries treated in a trauma center, accounting for 36 to $59 \%$ of all facial fractures ${ }^{4}$. Young men are more predisposed to trauma in the second and third decades of life owing to the fact that they frequently engage in outdoor and high risk activities ${ }^{5}$. The most favorable sites of fractures (in descending order) in the mandible are the parasymphysis, body, angle, condylar region, symphysis and coronoid process ${ }^{6}$.

Muhammad Asif Shahzad
Associate Professor, Department of Oral \& Maxillofacial
I Surgery, Lahore Medical \& Dental College, Lahore
Email: drasif_395@hotmail.com
Momin Ayub Marath
Associate Professor, Department of Oral Pathology, Lahore
Medical \& Dental College, Lahore
Daud Mirza
Associate Professor and HOD, Department of Oral Pathology,
| I
I Received: 14-03-2018
I Revised: 04-05-2018
I Accepted: 08-05-2018

The etiologies of mandibular fractures, incidence and patterns tend to vary with geographic region, socioeconomic status, culture, environmental and technologic factors. Therefore the main cause for mandibular fractures described in literature remains inconsistent ${ }^{7}$. Road traffic accident (RTA) has been reported as the leading etiology in the developing nations, while incidence due to personal violence is more in developed countries $^{8,9}$.

Since the last few decades, open reduction and internal fixation (ORIF) using titanium miniplates has become the treatment of choice whenever possible. This has resulted in improved oral hygiene, mouth opening, better speech and patient's earlier return to function and work. Also, a decreased preference and decline has been recorded in the use of wire osteosynthesis and closed reduction and indirect fixation (CRIF) techniques ${ }^{10,11}$.

Over the years, the epidemiology of mandibular fractures keeps changing and new trends in etiology, pattern of presentation and management are constantly evolving ${ }^{12}$. This, therefore, necessitates a constant appraisal of these fractures injuries in order to keep abreast with recent developments and changing pattern of their management.

The objective of current study was to evaluate the etiological factors, patterns of presentation, frequency and different treatment modalities for mandibular fractures in patients treated at Lahore Medical and Dental College/Ghurki Trust Teaching Hospital (LMDC/GTTH). This study, in turn, will help the health care providers in a clearer understanding of 
the different etiological factors involved and pattern of mandibular fractures while managing these injuries. The study may also provide circumstantial evidence for the recommendation of possible preventive measures and enforcement of seat belt legislation.

\section{METHODOLOGY:}

This study was conducted in the Department of Oral and Maxillofacial Surgery, Lahore Medical Dental College / Ghurki Trust Teaching Hospital, Lahore from March 2015 to September 2017.

The patients attending the Accident and Emergency Department as well as Outpatient Section/Department of Oral and Maxillofacial Surgery at Lahore Medical \& Dental College / Ghurki Trust Teaching Hospital, Lahore were thoroughly assessed.

All the consecutive patients of any age and either gender having clinical and radiological evidence of mandibular fractures were included in the current study. Medically compromised, previously maltreated and untreated patients were excluded.

The patients were assessed with thorough history and clinical examination and information obtained was filled up in the patient's departmental records. Specific radiographs such as OPG (orthopentomogram) and PA (postero anterior) mandible were obtained to confirm the bony fractures. CT scan and intra-oral radiographs (periapical/occlusal) were prescribed if needed. Classification of fractures was done using standard nomenclature. An appropriated treatment plan was devised and executed after obtaining written informed consent of the patient. The pattern and management of mandibular fractures were compiled according to age, gender, etiology, anatomic site, relative frequency and methods of fixation.

Open reduction and internal fixation (ORIF) under GA (general anesthesia) was the preferred method of treatment for the mandibular fractures whenever possible (Fig $4 \& 5$ ). However, closed reduction and indirect fixation techniques were also used for mandibular fractures, with patients under local anesthesia (LA). IMF (intermaxillary fixation) with eyelet wiring was performed for patients who were unable to undergo GA, having financial issues and favourable mandibular fractures without significant displacement. While IMF (arch bar with elastics) was preferably used for condylar fractures. The patients below 12 years (in primary/mixed dentition) were treated under GA because of their uncooperative behavior. Splint fixation under GA was the method of choice for pediatric patients along with edentulous patients with atrophic mandible. A follow up of six weeks was done for all the patients.

The data collected from departmental records was analyzed using SPSS version 20. The qualitative variables like gender, etiology, pattern, anatomic site and treatment modalities were presented as frequency and percentages. While quantitative variable like age was presented by mean and standard deviation. A value of $\mathrm{p}<0.05$ was considered significant with a confidence interval of $95 \%$. We did not apply any inferential test as the study was descriptive in nature.

\section{RESULTS:}

During the period of March 2015 to September 2017, a total of 112 patients with 189 mandibular fractures were managed at Lahore Medical and Dental College/Ghurki Trust Teaching Hospital (LMDC/GTTH).

The patients' ages were between 3 to 55 years $(24.87 \pm 10.867$, mean/SD). The majority of fractures occurred amongst the 21-30 years of age group $(n=49 ; 43.75 \%)$. There were 17 females and 95 males with female to male ratio of 1:5.6 (Figure 1).

Road traffic accident (RTA) was the most frequent etiology in $89(79.46 \%)$ of patients, followed by assaults $11(09.82 \%)$, fall $09(08.04 \%)$ and sports $02(01.79 \%)$ (Figure 2).

The location and anatomical positions of fractures were determined in the mandible. 189 lines were detected in 112 patients with fractured mandibles, which were due to variations in mandibular fractures in each patient. It gave a mean of 1.7 fractures per patient.

Out of 189 fractures, the most prominent site of mandibular fractures was parasymphysis $(\mathrm{n}=82 ; 43.39 \%)$, followed by condyle $(\mathrm{n}=43 ; 22.75 \%)$, angle $(\mathrm{n}=30 ; 15.87 \%)$, body $(n=20 ; 10.58 \%)$, dentoalveolar $(n=6 ; 3.17 \%)$, symphysis $(\mathrm{n}=5 ; 02.65 \%)$, ramus $(\mathrm{n}=2 ; 01.06 \%)$, and coronoid $(\mathrm{n}=1 ; 0.53 \%)$ (Table 1$)$.

By excluding the symphysis and dentoalveolar fractures, out of 178 fractures, $98(55.06 \%)$ were present on the right side and $80(44.94 \%)$ on the left side. The mandible had a single fracture (unifocal) in 43(38.39\%) of cases, 61(54.47\%) had two fractures (bifocal) and 08(07.14\%) with three fractures (trifocal) in mandible. The most common combinations in 112 patients were parasymphysis/condyle $(\mathrm{n}=27 ; 24.11 \%)$, followed by parasymphysis/angle $(\mathrm{n}=21$; $18.75 \%)$, body/angle ( $\mathrm{n}=04 ; 03.57 \%)$, parasymphysis/body $(n=3 ; 02.68 \%)$ and $(n=2 ; 1.79 \%)$ body/condyle.

The mandibular fractures were managed by using different treatment modalities of reduction and fixation (Figure 3). Out of the 112 patients, the technique of ORIF using miniplates was applied in 51(45.54\%). 09(08.03\%) were treated by ORIF with additional postoperative IMF using eyelet wiring, while ORIF with postoperative IMF using arch bar and elastics were used in $28(25.00 \%)$ of patients. The additional IMF was used in these patients due to multiple mandibular fractures usually in association with condylar region. Closed reduction and indirect fixation (CRIF) alone was the treatment of choice in 24(21.43\%) of the patients, namely a non surgical approach of IMF. $06(0.5 .36 \%)$ of 
them used IMF (with eyelet wiring) and 05 (04.47\%) by IMF (with arch bar and elastics), mainly used to treat condylar fractures. Also 06 (05.36\%) used wire composite splinting/or

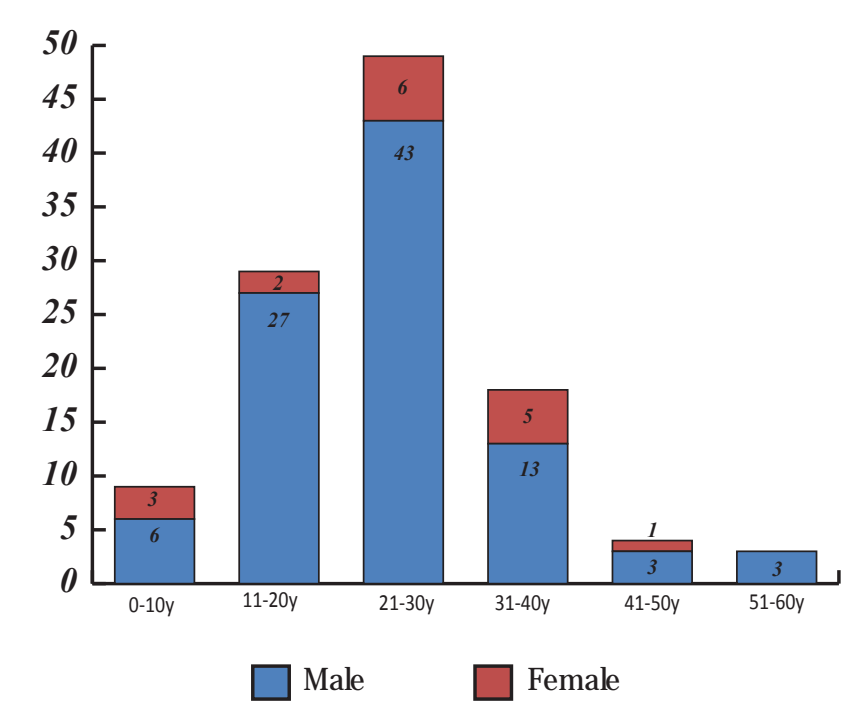

Figure 1: Age and Gender Distribution

Figure 1: Age and Gender Distribution arch bar. In $07(06.25 \%)$ of pediatric patients, occlusal splint fixation with circum-mandibular wiring was used as the treatment of choice, while $02(01.79 \%)$ of the children were treated by ORIF with resorbable miniplates.

\begin{tabular}{|l|c|c|}
\hline \multicolumn{1}{|c|}{ Fracture Site } & $\begin{array}{c}\text { No of } \\
\text { Fracture } \\
\mathrm{n}=189)\end{array}$ & $\%$ \\
\hline Symphysis & 05 & 02.65 \\
\hline Parasymphysis & 82 & 43.39 \\
\hline Body & 20 & 10.58 \\
\hline Angle & 30 & 15.87 \\
\hline Condyle & 43 & 22.75 \\
\hline Ramus & 02 & 01.06 \\
\hline Dentoalveolar & 06 & 03.17 \\
\hline Coronoid & 01 & 00.53 \\
\hline Total & 189 & 100.00 \\
\hline
\end{tabular}

Table 1: Anatomical Location of Mandibular Fractures

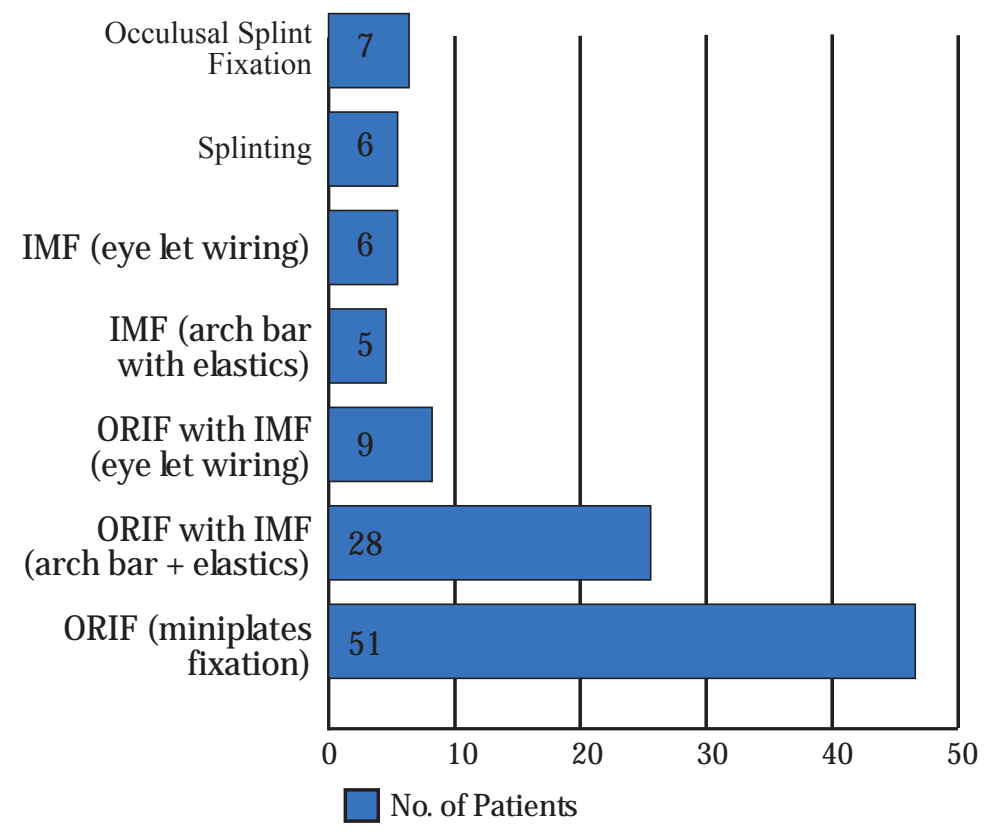

Figure 3: Treatment Modalities for Mandibular Fractures 


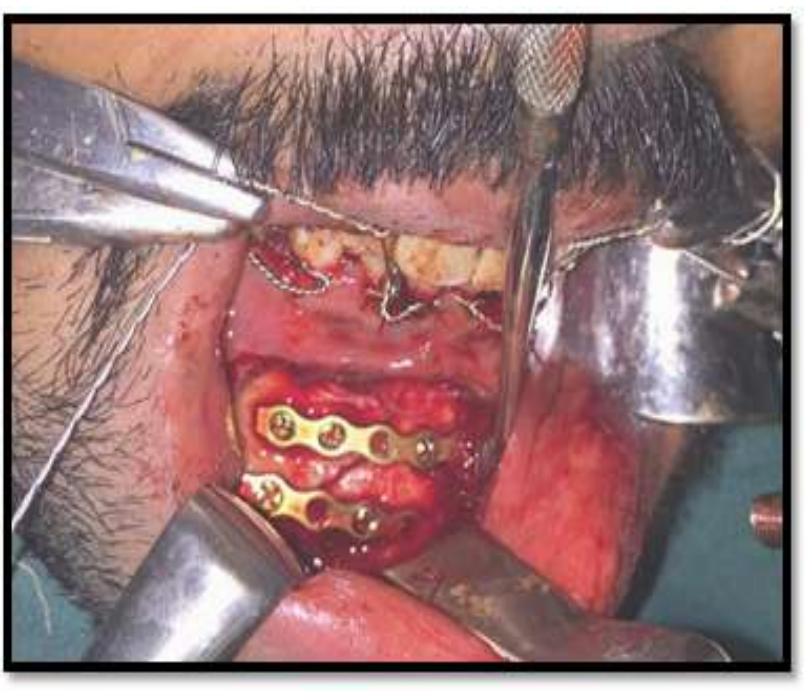

Figure 4: Open reduction and internal fixation (ORIF) of parasymphyseal fracture $(\mathrm{R})$ with titanium miniplates

\section{DISCUSSION:}

All over the world, maxillofacial injuries have continued to generate discussion among researchers, due to the functional and cosmetic deformities affecting the victims. The etiological factors, incidence and pattern of mandibular fractures tend to vary with geographic region, socioeconomic status, culture, religion and $\mathrm{era}^{13}$. Most of the literature confirms the predominance of mandibular trauma in 21-30 years of age group ${ }^{9,14}$. This assertion is supported by our study in which $49(43.75 \%)$ of patients were between the ages of 21 to 30 years. The possible explanation can be attributed to the fact is that people in this age group take part in dangerous exercises and sports, careless driving of motor vehicles and are more likely to be involved in violence.

A higher frequency of mandibular fractures in males than females has been reported in most of the conducted studies ${ }^{9,15}$. In present study it remained 5.6:1, that is higher than reported by Boffano et $\mathrm{al}^{13}(2.2: 1)$. This finding is understandable and could be related to the fact that men are active and more exposed, due to their more frequent participation in outdoor and high risk activities such as driving vehicles, and sports that involve physical contact. Men are also more involved in violent interaction along with drugs and alcohol habits.

Our study highlights that road traffic accident (79.46\%) was the most frequent etiology of mandibular, followed by assault $(09.82 \%)$, fall $(08.04 \%)$ and sports $(01.79 \%)$, which is in agreement with other studies conducted in developing countries $^{14,16}$, while other studies have reported the assault as the most common cause of fracture ${ }^{17}$. Apart from RTA and assaults, other common cause of mandibular fractures include sporting injuries, falls, domestic accidents and industrial injuries ${ }^{12}$. These etiological variations reflect differences in the socio-economic factors, national infrastructure development(particularly roadways, traffic regulations and legislation) and other behavioral habits, such

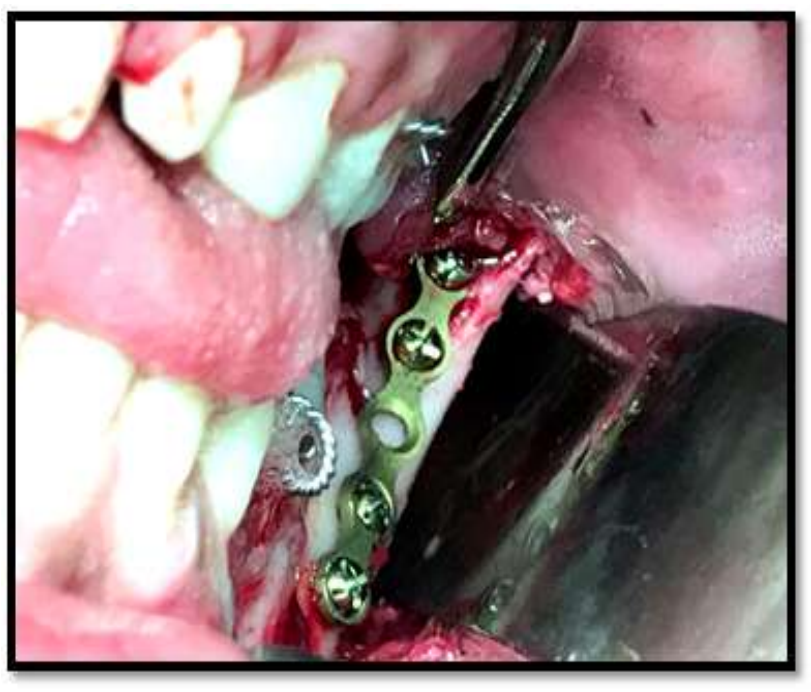

Figure 5: (ORIF) of mandibular angle fracture (L)

as alcohol consumption or criminal activities. The reasons for this higher rate of RTA in our region include poor road networks, improper licensing of drivers/riders, non usage of seatbelts, neglect of helmets by motorbike riders, addiction of drugs or alcohol and non compliance with traffic rules among others.

As revealed by the current study, the most prominent site of fracture in mandible was the parasymphysis region $(43.39 \%)$, which is consistent with the findings of Sunita Malik et $\mathrm{al}^{18}$. However, the present study was not in agreement with the results of $\mathrm{Nair}^{19}$ and Adebayo ${ }^{20}$ who showed the body as the most common site, whereas Van Beek ${ }^{21}$ observed the condyle and Chalya $\mathrm{et}_{\mathrm{al}} \mathrm{l}^{22}$. stated the angle region as the most frequent site of fracture. The parasymphysis/condyle $(n=27 ; 24.11 \%)$, has been described as the most frequent combination in mandibular fractures, followed by parasymphysis/angle $(n=21 ; 18.75 \%)$, These finding are consistent with the observations of Ogundare et al. ${ }^{23}$ However, Abiose $^{24}$ reported bilateral body as the most frequent mandibular fracture combination. The particular reason for these variations is difficult to describe but one can assume that inter-population difference in the sites of maxillofacial fractures may be attributed to the diverse etiologic factors involved.

Over the last few decades, open reduction and internal fixation (ORIF) using titanium miniplates has become the treatment of choice whenever possible ${ }^{10,11,25,26}$. Open reduction and internal fixation (ORIF/ORIF with IMF) was performed in $88(78.57 \%$ ) of patients while closed reduction and indirect fixation (IMF with eyelet wiring/arch bar elastics \& splint fixation) was done in $24(21.43 \%)$ of patients. All the treatment modalities were used without any device for external fixation achieving satisfactory results.

Al Moraissi et $\mathrm{al}^{25}$ and Ellis E $\mathrm{III}^{26}$ has also recommended 
the use of ORIF, whenever possible. Whereas Chandra ${ }^{27}$ and Kilasara ${ }^{28}$ found that most of the mandibular fractures could be managed by closed reduction. The method of ORIF has been advocated to be the "gold standard" for the treatment of mandibular fractures. This has resulted in improved oral hygiene, mouth opening, better speech and patient's earlier return to function and work. However, this form of treatment has not become popular in our country due to lack of expertise (i.e. maxillofacial surgeons) and reduced facilities for open reduction and internal fixation; even when available, the cost of the treatment is usually prohibitive.

\section{CONCLUSION/RECOMMENDATIONS:}

This current study shows that the majority of fractures occurred amongst the 21-30 years of age group having female to male ratio of 1:5.6. Road traffic accident (RTA) was the most frequent etiological factor for mandibular fractures. Among the mandibular fractures, the most common site involved was the parasymphysis followed by condylar region. The most frequent technique used was ORIF/ORIF with IMF of patients.

As evidenced by the present study that the road traffic accidents are the leading cause of mandibular fractures in young adults, mostly due to traffic rules violations. These finding should alert the authorities to the need for the enforcement of existing traffic laws to control excessive speed on highways and careless driving; provision of better roads; and the use of safety belts is to be made compulsory. It is also recommended that there is need of cooperation and coordination among the various medical disciplines for a rapid management of maxillofacial injuries which might prevent functional as well as aesthetic morbidity.

\section{REFERENCES:}

1. Olusanya AA, Adeleye AO, Aladelusi TO, Fasola AO. Updates on the epidemiology and pattern of traumatic maxillofacial injuries in a nigerian university teaching hospital: a 12-month prospective cohort in-hospital outcome study.Craniomaxillofac Trauma Reconstr.2015; 8(1): 50-58.

2. Bart van den Bergha, K. HakkiKaragozoglua, Martijn W. Heymansb, Tymour Forouzanfara. Aetiology and incidence of maxillo facial trauma in Amsterdam: A retrospectiveanalysis of 579 patients. J Cranio maxillofac Surg. 2012; 40(6): 165169.

3. Ellis E, Moos KF, el-Attar A. Ten years of mandibular fractures: an analysis of 2137 cases. Oral Surg Oral Med Oral Pathol 1985; 59(2): 120-9.

4. Van Hoof RF, Merkx CA, Stekelenburg EC. The different patterns of fractures of the facial skeleton in four European countries. Int J Oral Surg 1977; 6(1): 3-11.

5. Singaram M, G SV, Udhayakumar RK. Prevalence, pattern, etiology and management of maxillofacial trauma in a developing country: a retrospective study. J Korean Assoc Oral Maxillofacsurg. 2016; 42(4): 174-181.

6. Oruc M, Isik VM, Kankaya Y, Gursoy K, Sungur N, Aslan $\mathrm{G}$ et al. Analysis of fractured mandible over two decades. J CraniofacSurg 2016; 27(6): 1457-61.
7. Oikarinen K, Ignatius E, Kauppi H, Silvennoinen U. Mandibular fractures in Northern Finland in the 1980's: A 10 year study. Br J Oral Maxillofac Surg 1993; 31: 23-27.

8. Schön R, Roveda SI, Carter B. Mandibular fractures in Townsville, Australia: incidence, aetiology and treatment using the 2.0 AO/ASIF miniplate system. Br J Oral Maxillofac Surg 2001; 39(2): 145-8.

9. Umar KB, Shuja RA, Ahmad K, Mohammad TK, Abdus S. Occurrence and characteristics of maxillofacial injuries - A Study. Pakistan Oral \& Dental Journal, 2010; 30: 57-61.

10. Rix L, Stevenson ARL, Punnia-Moorthy A. An analysis of 80 cases of mandibular fractures treated with miniplate osteosynthesis. Int J Oral Maxillofac Surg, 1991; 20: 337341.

11. Renton TF, Wiesenfeld D. Mandibular fracture osteosynthesis: a comparison of three techniques. Br J Oral Maxillofac Surg, 1996; 34: 166-173.

12. Mijiti A, Ling W, Tuerdi M, Maimaiti A, Tuerxun J, Tao YZ, et all. Epidemiological analysis of maxillofacial fractures treated at a university hospital, Xinjiang, China: A 5-year retrospective study.J CraniomaxillofacSurg.2014; 42(3): 227233.

13. Boffano P, Roccia F, Zavattero E, Dediol E, Uglesic V, Kovacic Z, et al. European Maxillofacial Trauma (EURMAT) project: a multicentre and prospective study. Jcraniomaxillofacsurg . 2015; 43(1): 62-70.

14. Wimon S, Kasemsak P. The Epidemiology of Mandibular Fractures Treated at Chiang Mai University Hospital: A Review of 198 Cases. J Med Assoc Thai, 2008; 91: 868-74.

15. Qudah MA, Al-Khateeb T, Bataineh AB, Rawashdeh M. Mandibular fractures in Jordanians: a comparative study between young and adult patients. J Craniomaxillofac Surg 2005; 33: 103-6.

16. Tugaineyo EI, Odhiambo WA, Akama MK, Guthua SW, Dimba EA. Aetiology, pattern and management of oral and maxillofacial injuries at mulago national referral hospital. East Afr Med J. 2012; 89(11): 351- 358.

17. Asadi SG, Asadi Z. The aetiology of mandibular fractures at an urban centre. J Roy Soc Health 1997; 117: 164-167.

18. Sunita Malik et al. Analysis of maxillofacial trauma at Rohtak (Haryana), India: five years prospective study. Journal of Maxillofacial Trauma 2012; 1(2): 43-50.

19. Nair BK, Paul G. Incidence and aetiology of maxillofacial skeleton in Trivandrum- A retrospective study. Br J Oral Maxillofac Surg, 1986, 24: 40-43.

20. Adebayo ET, Ajike OS, Adekeye EO. Analysis of the pattern of Maxillofacial fractures in Kaduna,Nigeria. Br J Oral and Maxillofac Surg 2003, 41(6): 396-400,

21. Van Beek GJ, Merkx CA. Changes in the pattern of fractures of the maxillofacial skeleton. Int J Oral maxillofac Surg, 1999, 28(6): 424-428.

22. Chalya et al. Etiological spectrum, injury characteristics and treatment outcome of maxillofacial injuries in a Tanzanian teaching hospital. Journal of Trauma Management \& Outcomes 2011, 5: 7 .

23. Ogundare BO, Bonnick A, Bayley N. Pattern of mandibular fractures in an urban major trauma center. J Oral Maxillofac Surg 2003; 61(6): 713-8.

24. Abiose BO. Maxillofacial skeleton injuries in the western 
states of Nigeria. Br J Oral Maxillofac Surg, 1986; 24: 3139.

25. AlMoraissi EA, Ellis E. Surgical management of anterior mandibular fractures: a systematic review and metaanalysis. J Oral Maxillofac Surg. 2014; 72(12): 250-57.

26. Ellis E III. Open reduction and internal fixation of combined angle and body/symphysis fractures of the mandible: how much fixation is enough? J Oral Maxillofac Surg. 2013; 71(4): 726-733.
27. Chandra Shekar BR, Reddy C. A five-year retrospective statistical analysis of maxillofacial injuries in patients admitted and treated at two hospitals of Mysore city. Indian J Dent Res 2008; 19: 304-8.

28. Kilasara DB, Mecky IM, Shubi F. Epidemiology and management of maxillofacial fractures treated at Muhimbili National Hospital in Dar es Salaam, Tanzania 1998-2003. International dental journal 2006; 56: 131-134. 